\title{
Desenvolvimento de adoquim cerâmico com argilas cauliníticas, chamote e argilito
}

\section{(Development of ceramic paver with kaolinitic clays, grog and argillite)}

\author{
V. S. Candido, R. M. Pinheiro, S. N. Monteiro, C. M. F. Vieira \\ Laboratório de Materiais Avançados - LAMAV, Universidade Estadual do Norte Fluminense - UENF, Av. Alberto \\ Lamego 2000, Campos dos Goytacazes, RJ 28013-602, Brasil \\ v.scarpini@yahoo.com.br
}

\begin{abstract}
Resumo
Este trabalho tem por objetivo desenvolver uma massa cerâmica com argilas cauliníticas, chamote e argilito visando à obtenção de pavimento intertravado tipo adoquim. Inicialmente, as matérias-primas foram submetidas a ensaios de caracterização física, química e mineralógica. Corpos-de-prova cilíndricos foram preparados por prensagem uniaxial a $20 \mathrm{MPa}$ e queimados em forno tipo mufla a $850{ }^{\circ} \mathrm{C}$. As propriedades tecnológicas avaliadas foram: absorção de água, retração diametral e resistência à compressão uniaxial. A análise microestrutural das composições foi feita por microscopia eletrônica de varredura. Os resultados indicaram que o argilito reduziu significativamente a absorção de água e a retração das composições. O chamote reduziu a retração diametral de queima e a resistência mecânica. Quanto à absorção de água o chamote não alterou significativamente esta propriedade. A melhor formulação desenvolvida é constituída por $50 \%$ em peso de argilas e $50 \%$ de argilito.

Palavras-chave: adoquim, argila, argilito, cerâmica vermelha, chamote.
\end{abstract}

\section{Abstract}

This work has for objective the development a ceramic body for ceramic paver using kaolinitic clays, argillite and grog. The raw materials were submitted to physical, chemical and mineralogical tests. Cylindrical specimens were uniaxially mold-press and then fired at $850^{\circ} \mathrm{C}$. The evaluated technological properties were: water absorption, diametral shrinkage and uniaxial compressive strength. The microstructure of the fired ceramics was evaluated by electron scanning microscopy. The results show that the argillite significantly decreased the water absorption and the shrinkage of the clayey body. The grog also decreased the shrinkage, but also decreased the mechanical strength. With respect to the water absorption, the grog did not change this property of the composition elaborated with clays and argillite. The best development formulation is constituted by $50 \mathrm{wt} \%$ of clays and $50 \%$ by argillite.

Keywords: ceramic paver, clay, argillite, red ceramic, grog.

\section{INTRODUÇÃO}

O pavimento rústico cerâmico, adoquim, é um produto não decorado cujas principais características são, entre outras, sua coloração natural e aspecto rústico [1]. O adoquim é pequeno e de fácil manejo, suas formas geométricas foram desenvolvidas, não só para obter facilidade de instalação, mas também para uma correta distribuição de cargas impostas pelos diversos tipos de tráfego. Suas geometrias permitem uma diversidade de combinações, proporcionando um ambiente com uma estética harmoniosa. Os adoquins permitem a pavimentação de estradas para todos os tipos de tráfego, calçadas, zonas de pedestres, pátios e jardins, dentre outros [2]. Esse tipo de material é produzido a partir de uma mistura de argilas naturais que proporcionam plasticidade e coloração desejada com materiais não plásticos, como o chamote e $\mathrm{o}$ argilito. Essa mistura pode facilitar a etapa de secagem e conferir padrão estético desejado [3]. O chamote, material de refugo de materiais cerâmicos descartado após queima, é um dos resíduos industriais que podem, eventualmente, ser incorporado à argila após trituração para produção de adoquim cerâmico [4]. A utilização do chamote pode ter reflexos positivos em toda a cadeia produtiva. Esse material geralmente possui granulometria mais grosseira que a argila o que favorece melhor empacotamento [4-5]. Além disso, a morfologia das partículas pode favorecer um aumento da permeabilidade da peça verde, facilitando a eliminação da água de conformação [1]. Durante a queima o chamote se comporta como material inerte até a temperatura na qual foi obtido podendo se tornar um ponto de concentração de tensão diminuindo assim a resistência mecânica da peça [6]. Entretanto quando é queimado acima de sua temperatura de processamento inicial as reações e as transformações de sinterização que venham a ocorrer pode contribuir para minimizar ou até mesmo eliminar o efeito deletério na resistência mecânica [6].

$\mathrm{O}$ argilito, uma rocha de origem sedimentar [7], é um material comumente empregado na fabricação de telhas e blocos cerâmicos na região de Itú, SP. Uma vez que a 
sua composição química e mineralógica é similar às das argilas da região, este material atua como um inerte durante a secagem e apresenta, durante a queima, comportamento físico-químico similar ao da argila. Esse comportamento pode favorecer sua incorporação às argilas da região de Campos dos Goytacazes, RJ, e assim contribuir para a fabricação do adoquim cerâmico.

Este trabalho tem o objetivo de avaliar a influência da adição de chamote, obtido de rejeito de blocos de vedação queimados em baixas temperaturas, e do argilito oriundo da cidade de Itú, SP, em massa cerâmica para produção de pavimento intertravado tipo adoquim, produto em desenvolvimento na região.

\section{MATERIAIS E MÉTODOS}

Foram utilizados dois tipos de argilas cauliníticas, argilito de Itú e chamote de blocos de vedação queimados a $600{ }^{\circ} \mathrm{C}$. As matérias-primas foram submetidas a ensaios de caracterização física, química e mineralógica. A composição química dos materiais foi obtida por fluorescência de raios X em equipamento Philips PW2400. A análise das fases cristalinas foi feita por difração de raios X (DRX) em difratômetro XRD6000 Shimadzu operando com radiação $\mathrm{Cu}-\mathrm{k}_{\alpha}$ e varredura de $2 \theta$ de 5 a $60^{\circ}$. A distribuição de tamanho de partícula das matérias-primas foi obtida por meio do método de peneiramento e sedimentação por gravimetria [8]. A análise termogravimétrica foi feita em aparelho termoanalisador Netzsch STA 409C, com taxa de aquecimento $10{ }^{\circ} \mathrm{C} / \mathrm{min}$. Após a caracterização das matérias-primas, foram elaboradas três composições, mostradas na Tabela I, contendo massa argilosa, argilito e chamote. A massa argilosa, composição A, é constituída da mistura em partes iguais de duas argilas cauliníticas da região. A composição $\mathrm{B}$ corresponde à mistura da massa argilosa com $50 \%$ em peso de argilito. Já na composição C, o chamote foi incorporado na quantidade de $10 \%$ em peso em substituição à massa argilosa.

Tabela I - Composição investigadas (\% em peso). [Table I - Investigated composition (wt. \%).]

\begin{tabular}{cccc}
\hline \multicolumn{4}{c}{ Matérias-primas (\% em peso) } \\
\hline Composições & $\begin{array}{c}\text { Massa } \\
\text { argilosa }\end{array}$ & Argilito & Chamote \\
\hline A & 100 & - & - \\
B & 50 & 50 & - \\
C & 40 & 50 & 10 \\
\hline
\end{tabular}

Posteriormente, as formulações foram umedecidas com $8 \%$ de água para a preparação, por prensagem uniaxial, de corpos-de-prova cilíndricos com diâmetro $20,28 \mathrm{~mm}$. A densidade dos corpos-de-prova variou de $1,95 \mathrm{~g} / \mathrm{cm}^{3}$ a 2,09 $\mathrm{g} / \mathrm{cm}^{3}$. Os corpos-de-prova após conformação foram secos à temperatura ambiente por $24 \mathrm{~h}$, e posteriormente secos em estufa a $110{ }^{\circ} \mathrm{C}$. A queima foi em forno EDG 3P-S a
$850{ }^{\circ} \mathrm{C}$. A taxa de aquecimento foi $2{ }^{\circ} \mathrm{C} / \mathrm{min}$. Os corpos-deprova foram mantidos na temperatura patamar por $30 \mathrm{~min}$ e resfriados por convecção natural desligando-se o forno.

As propriedades tecnológicas determinadas foram: retração diametral de queima, absorção de água e resistência à compressão uniaxial.

As amostras para a análise microestrutural foram previamente cortadas em equipamento da Struers Minitron e metalizadas em metalizador Baltec SCD050 Sputter Coater. Posteriormente as cerâmicas foram analisadas por microscopia eletrônica de varredura em equipamento Jeol JSM 6460LV.

\section{RESULTADOS E DISCUSSÃO}

$\mathrm{O}$ difratograma de raios $\mathrm{X}$ das matérias-primas utilizadas está apresentado na Fig. 1 (a, b, c e d). Nota-se que as argilas, Figs. 1a e 1b, apresentam composição mineralógica similar com presença de picos de difração referentes à caulinita, quartzo, mica muscovita e gibsita. A presença do mineral gibsita aumenta a refratariedade e a perda ao fogo das argilas [7]. O difratograma de raios $X$ do argilito, Fig. 1c, revela a presença de quartzo, a caulinita, a microclina e o feldspato sódico, a anortita. Como a composição mineralógica do argilito é bem similar às argilas, a utilização destas matériasprimas na composição da massa reduz o risco de aparecimento de tensões residuais durante o processamento. $\mathrm{O}$ chamote, Fig. 1d, apresenta como fase cristalina predominante quartzo e mica muscovita. Além disso, podem-se observar pequenos picos de hematita, bem como a presença de caulinita, evidenciando que o chamote foi obtido de peças que não tiveram sua temperatura de queima superior a $600^{\circ} \mathrm{C}$. Acima dessa temperatura, a caulinita perde sua água de constituição transformando-se numa fase amorfa, a metacaulinita [9].

A Tabela II apresenta a composição química das matériasprimas. Nota-se que as argilas, o argilito e o chamote apresentam elevada porcentagem em peso de $\mathrm{Fe}_{2} \mathrm{O}_{3}$ o que confere a cor avermelhada às cerâmicas. Observa-se também que as argilas apresentam menor teor de sílica associado a um elevado teor de alumina em comparação com o argilito. Essa característica está associada, sobretudo, ao elevado teor de argilominerais, do tipo caulinita, nas argilas. Isto pode ser comprovado com o maior teor de perda ao fogo (PF) das argilas. O chamote ainda apresenta perda ao fogo, o que está associado à perda de hidroxila remanescente da caulinita $\left(2 \mathrm{SiO}_{2} \cdot \mathrm{Al}_{2} \mathrm{O}_{3} \cdot 2 \mathrm{H}_{2} \mathrm{O}\right)$. São observados ainda, baixos teores relativos de óxidos alcalinos fundentes como $\mathrm{K}_{2} \mathrm{O}$ e $\mathrm{Na}_{2} \mathrm{O}$ nas argilas e no chamote se comparado ao argilito. $\mathrm{O}$ menor teor de alumina, maior teor de óxidos fundentes e menor perda ao fogo do argilito em comparação com as argilas investigadas são características extremamente favoráveis que devem contribuir para melhorar a qualidade da cerâmica, além de facilitar a trabalhabilidade por extrusão.

A Fig. 2 apresenta a curva de distribuição de tamanho de partícula das matérias-primas. A fração "argila" está associada a partículas com tamanho inferior a $0,002 \mathrm{~mm}$, de acordo com a classificação da International Society of Soil 

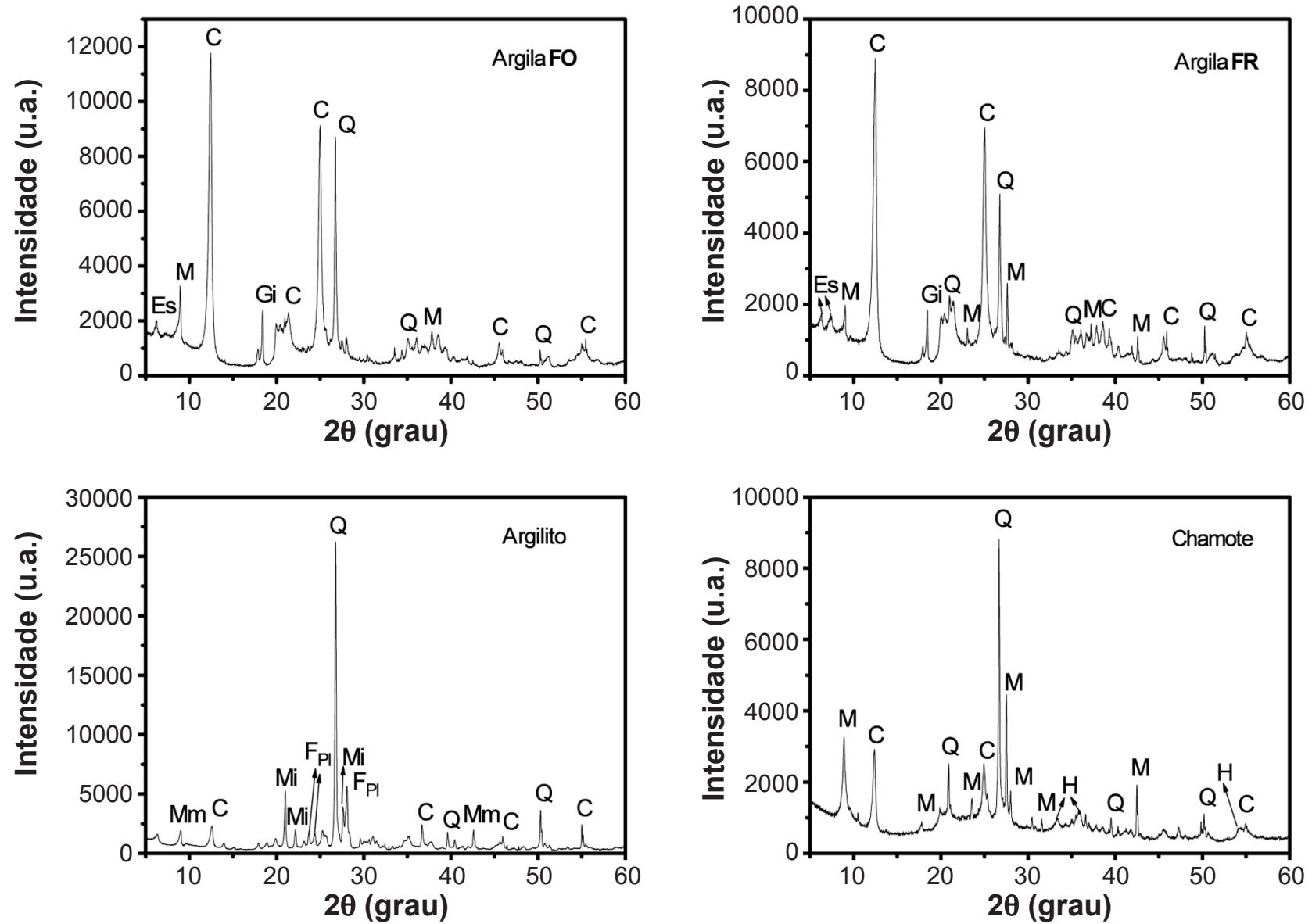

Figura 1: Difratogramas de raios $\mathrm{X}$ das matérias-primas. $\mathrm{C}=$ caulinita; $\mathrm{Q}=$ quartzo; $\mathrm{M}=$ mica muscovita; $\mathrm{H}=$ hematita; $\mathrm{Mm}=$ mineral micáceo; $\mathrm{Mi}=$ microclina; $\mathrm{F}_{\mathrm{Pl}}=$ feldspato plagioclásio.

[Figure 1: X-ray diffraction patterns for raw materials. $C=$ kaolinite; $Q=$ quartz; $M=$ muscovite mica; $H=$ hematite; $M m=$ micaceous mineral; $M i=$ microcline; $F_{P l}=$ plagioclase feldspar.]

Tabela II - Composição química das matérias-primas (\% em peso).

[Table II - Chemical composition of the raw materials (wt. \%).]

\begin{tabular}{ccccc}
\hline \multirow{2}{*}{ Composição } & \multicolumn{4}{c}{ Matérias-primas } \\
& Argilito Itú & Argila fraca & Argila Forte & Chamote \\
\hline $\mathrm{Fe}_{2} \mathrm{O}_{3}$ & 5,84 & 9,92 & 10,05 & 9,83 \\
$\mathrm{Al}_{2} \mathrm{O}_{3}$ & 16,34 & 21,61 & 26,78 & 32,18 \\
$\mathrm{MgO}$ & 2,29 & 0,86 & 0,71 & 0,85 \\
$\mathrm{Na}_{2} \mathrm{O}$ & 0,82 & - & - & - \\
$\mathrm{SiO}_{2}$ & 63,07 & 54,7 & 46,09 & 48,12 \\
$\mathrm{P}_{2} \mathrm{O}_{5}$ & 0,2 & 0,25 & 0,31 & 0,27 \\
$\mathrm{~K}_{2} \mathrm{O}$ & 4,02 & 2,47 & 1,66 & 1,78 \\
$\mathrm{CaO}$ & 0,48 & 0,57 & 0,34 & 0,41 \\
$\mathrm{TiO}$ & 0,79 & 1,35 & 1,59 & 1,47 \\
$\mathrm{MnO}$ & - & 0,17 & - & 0,17 \\
$\mathrm{P.F.}$ & 5,65 & 7,56 & 11,96 & 4,37 \\
\hline
\end{tabular}

Science [10]. As argilas estudadas, Fig. 2 (a), apresentam teor de fração argila igual a 50,01\% para argila forte, e $32,5 \%$ para argila fraca. O maior teor de "fração argila" na argila forte confere a ela maior plasticidade que a argila fraca, conforme será mostrado mais adiante.
$\mathrm{O}$ argilito e o chamote, Fig. 2b, apresentam granulometria mais grosseira em comparação as argilas. $\mathrm{O}$ baixo teor de fração argila do argilito, 14,97\%, confere a ele baixa plasticidade. Com relação à granulometria do chamote pode-se observar que esse resíduo apresenta um percentual 

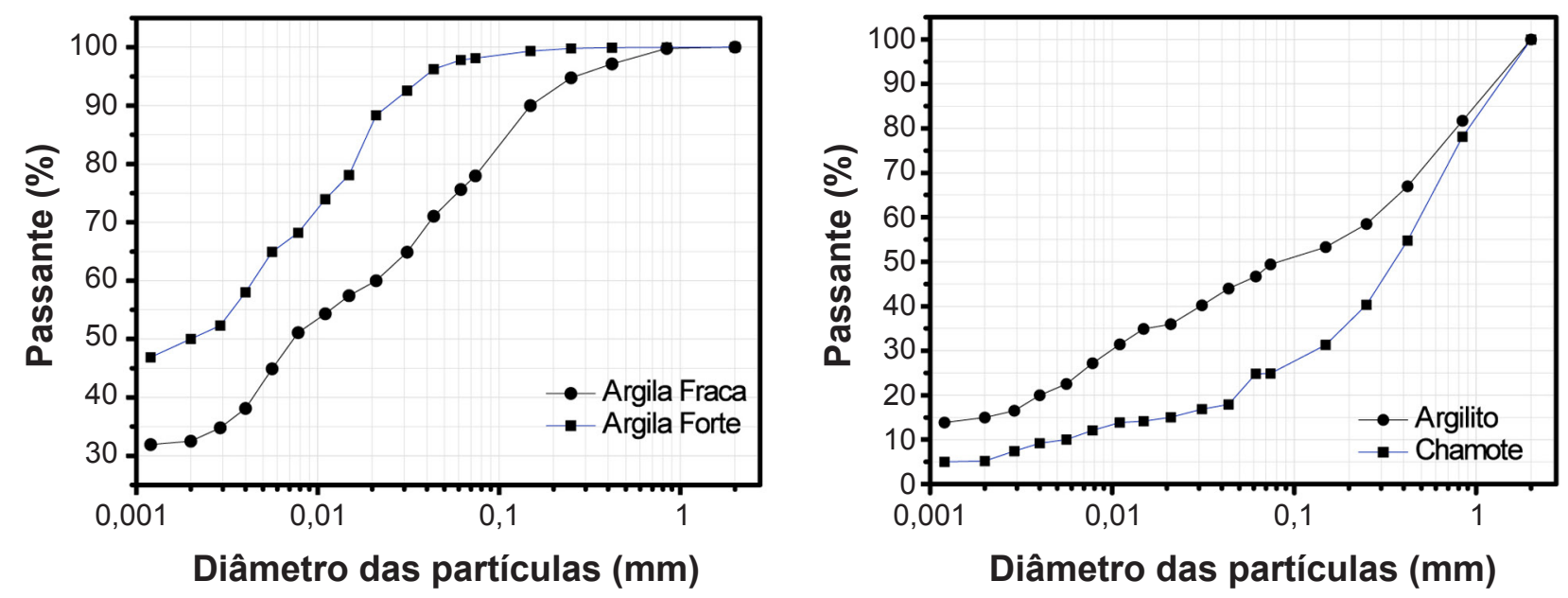

Figura 2: Distribuição de tamanho de partícula das matérias-primas. (a) argila forte e argila fraca, (b) argilito e chamote.

[Figure 2: Particle size distribution of raw materials. (a) strong clay and weak clay, (b) argillite and grog.]

de fração "argila" de 5,4\% em peso. As frações "silte" $(0,002$ a $0,02 \mathrm{~mm})$ e "areia" (de 0,02 a $2 \mathrm{~mm}$ ) são de $9,6 \%$ e $85 \%$, respectivamente. Esta granulometria do chamote, mais grosseira que a argila, pode facilitar o processo de secagem e melhorar o grau de empacotamento das cerâmicas [4].

A Fig. 3 mostra a localização das matérias-primas estudadas num gráfico elaborado a partir dos limites de plasticidade de Atterberg. A argila fraca localiza-se dentro da região aceitável de extrusão; a argila forte localiza-se acima da região aceitável apresentando excessiva plasticidade. $\mathrm{O}$ argilito encontra-se abaixo das regiões delimitadas apresentando baixa plasticidade, podendo atuar assim como um agente controlador desse parâmetro. O chamote embora não apresente plasticidade pode auxiliar na otimização da plasticidade da massa assim como o argilito.

A Fig. 4 mostra a retração diametral de queima das composições avaliadas. Nota-se que para a composição A, constituída somente pela massa argilosa, a retração diametral obteve maior valor. Com a adição de $50 \% \mathrm{em}$ massa de argilito e $10 \%$ em massa de chamote, a retração

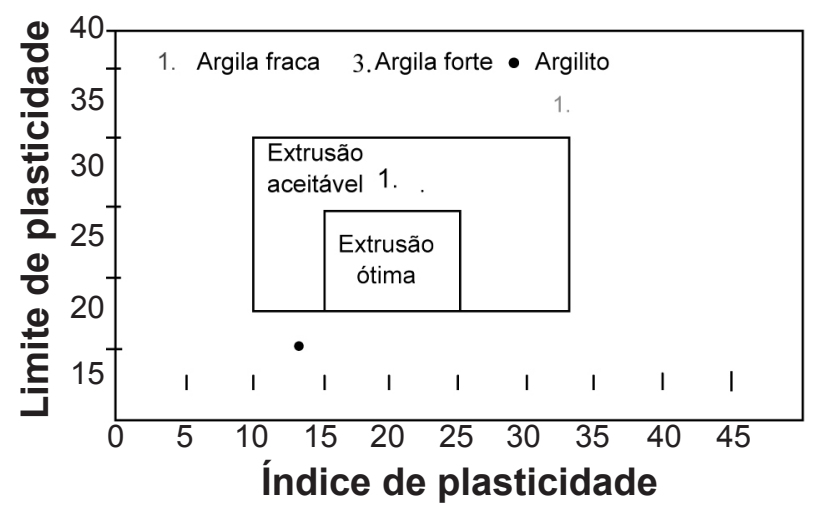

Figura 3: Prognóstico de extrusão das matérias-primas por meio dos limites de Atterberg.

[Figure 3: Extrusion prognostic of raw materials through the Atterberg limits.]

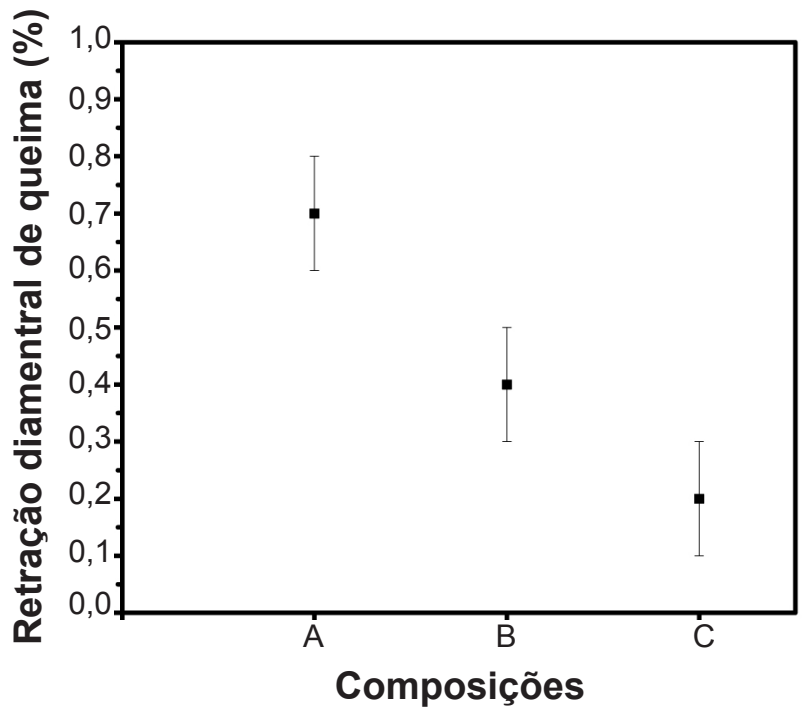

Figura 4: Retração diametral de queima das composições estudadas. [Figure 4: Diametral shrinkage of the evaluated compositions.]

diametral diminuiu em relação à composição $\mathrm{A}$, indicando que a adição do argilito e do chamote contribui para um controle dimensional das peças. Tal comportamento pode ser atribuído a menor formação de fase líquida durante a etapa de queima devido, provavelmente, à granulometria mais grosseira e à morfologia das partículas que diminuem a cinética de sinterização [11]. Além disso, há uma substituição da quantidade de material argiloso pelo argilito que apresenta menor perda ao fogo.

A densidade a seco das composições avaliadas está apresentada na Fig. 5. A adição de $50 \%$ de argilito à massa argilosa provocou um aumento de $0,09 \mathrm{~g} / \mathrm{cm}^{3}$. O valor de densidade obtido pela composição B foi $2,06 \mathrm{~g} / \mathrm{cm}^{3}$. Quando se adicionou de $10 \%$ de chamote à massa argilosa ocorreu uma diminuição na densidade da composição $C$ de $0,03 \mathrm{~g} / \mathrm{cm}^{3} \mathrm{em}$ comparação com a composição B. Em comparação à composição A, nota-se que a densidade aumentou com a adição do resíduo. 


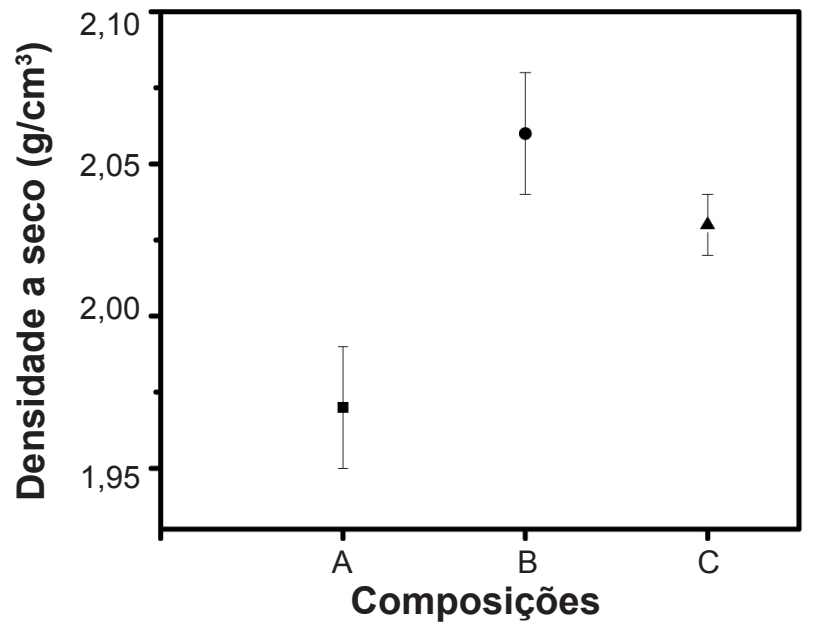

Figura 5: Densidade a seco das composições avaliadas.

[Figure 5: Dry bulk density of the evaluated compositions.]

Tal resultado indica que, de maneira geral, a adição de argilito e chamote contribuiu para um aumento na densificação a seco dos corpos-de-prova.

A absorção de água das composições estudadas está apresentada na Fig. 6. A composição A apresentou maior valor para esta propriedade em relação às outras amostras. As argilas usadas são argilas tipicamente cauliníticas que apresentam um comportamento refratário durante a etapa de queima acarretando elevada absorção de água [12]. Para a composição $\mathrm{C}$, contendo chamote, a absorção de água em relação à composição $\mathrm{B}$, dentro de um erro estatístico, não apresentou alterações significativas. Com relação à composição A, observa-se que houve uma diminuição dessa propriedade quando se adicionou o resíduo. Tal comportamento pode ser atribuído ao início do processo de formação de fase líquida e, também, ao maior empacotamento das partículas como observado na Fig. 4. A adição de argilito à massa também provocou uma diminuição da absorção de água. Esse comportamento pode ser atribuído à menor perda de massa do argilito, maior teor de fundentes em comparação

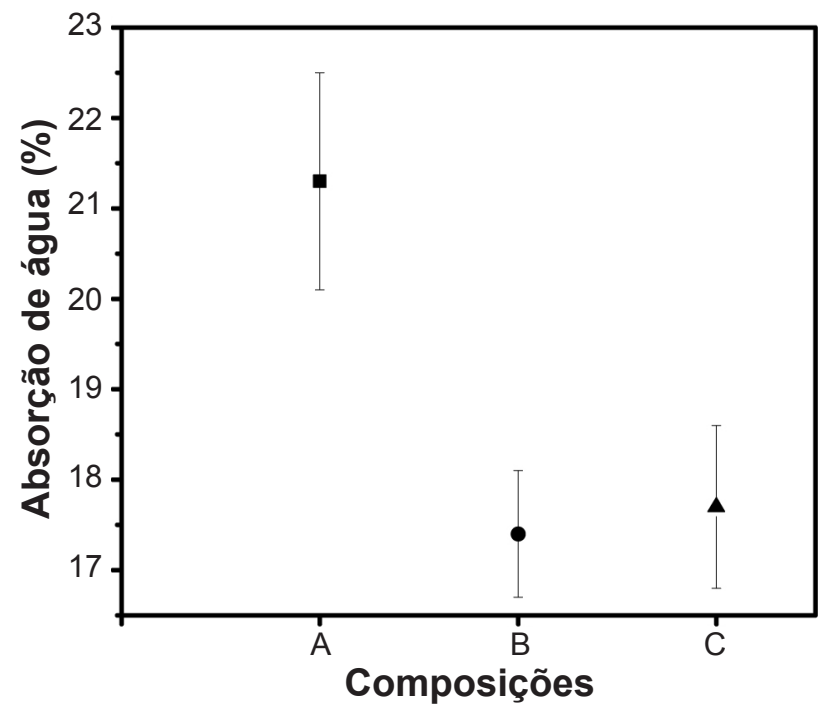

Figura 6: Absorção de água das composições avaliadas. [Figure 6: Water absorption of the evaluated compositions.] com as argilas cauliníticas [12] e, além disso, ao aumento da densidade a seco da composição $\mathrm{B}$ em relação a composição A.

No que se refere à resistência à compressão uniaxial, Fig. 7, observa-se que, dentro de um erro estatístico, não houve alteração significativa na resistência mecânica para as composições A e B. Esse comportamento pode ser atribuído às partículas grosseiras de quartzo e de aglomerados de argilito que contribuem para a estabilização da resistência mecânica. Entretanto, observa-se uma diminuição da resistência mecânica na composição com chamote, C. Tal diminuição pode estar associada à porosidade interna, porosidade intragranular e aglomerados de chamote que agem como grandes defeitos em combinação com a maior porosidade intergranular das composições [6].

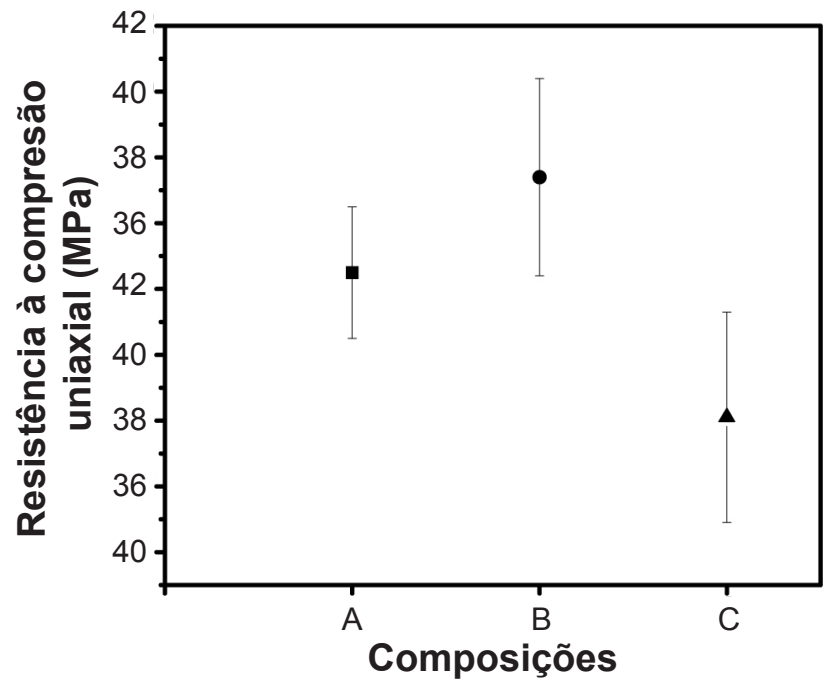

Figura 7: Compressão diametral das composições avaliadas. [Figure 7: Diametral compression of the evaluated compositions.]

No Brasil não existe uma norma que determine as propriedades tecnológicas para adoquim cerâmico. A norma existente é a ABNT 9781/1987 [13] para a produção de pavimento intertravado de cimento, principal concorrente do adoquim. De acordo com essa norma, a resistência à compressão axial deve ser $\geq 35,0 \mathrm{MPa}$ para veículos comerciais leves e $\geq 50,0 \mathrm{MPa}$ para veículos especiais ou cargas que produzem acentuados efeitos de abrasão Assim, seguindo a norma que rege a produção de pavimento intertravado de cimento, a formulação com adição de chamote poderia ser utilizada para a produção de adoquim cerâmico. Além disso, a composição $\mathrm{A}$, que alcançou valores próximos a $35 \mathrm{MPa}$, poderia ser utilizada em pavimentação intertravada que suporte baixa intensidade de sobrecarga. E ainda, a composição $\mathrm{B}$, que alcançou valores superiores a $35 \mathrm{MPa}$ atenderia a exigência para utilização em vias para tráfego de veículos comerciais leves [14]. De acordo com essa norma não existe nenhum valor que regulamente valores mínimos para vias de tráfego de pedestres, assim essas formulações atenderiam pavimentação para esse tipo de via. 

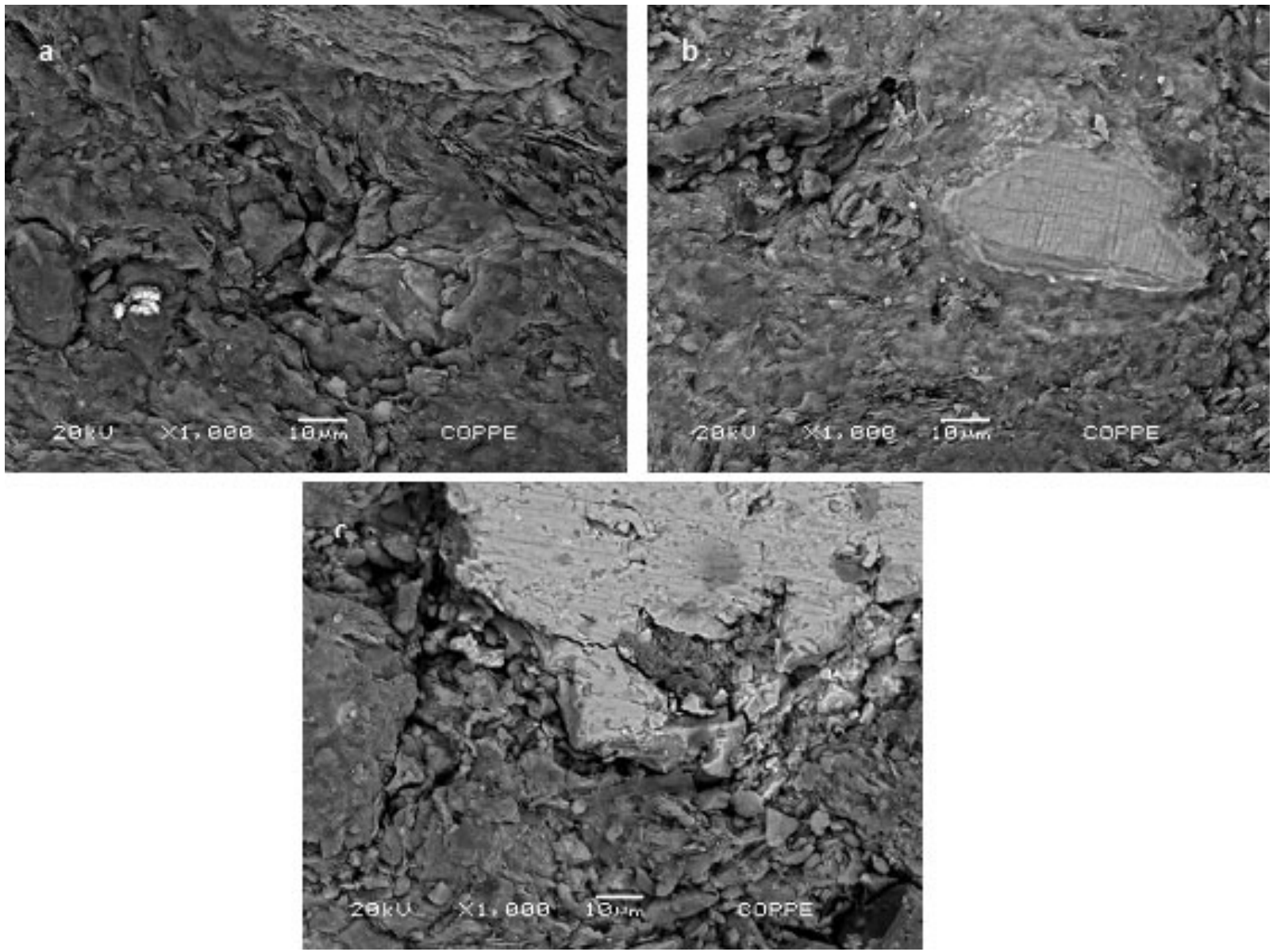

Figura 8: Micrografias obtidas por microscopia eletrônica de varredura das cerâmicas queimadas a $850{ }^{\circ} \mathrm{C}$; (a) A, (b) B, (c) C. [Figure 8: SEM micrographs of the fired ceramics at $850^{\circ} \mathrm{C}$; (a) A, (b) B, (c) C.]
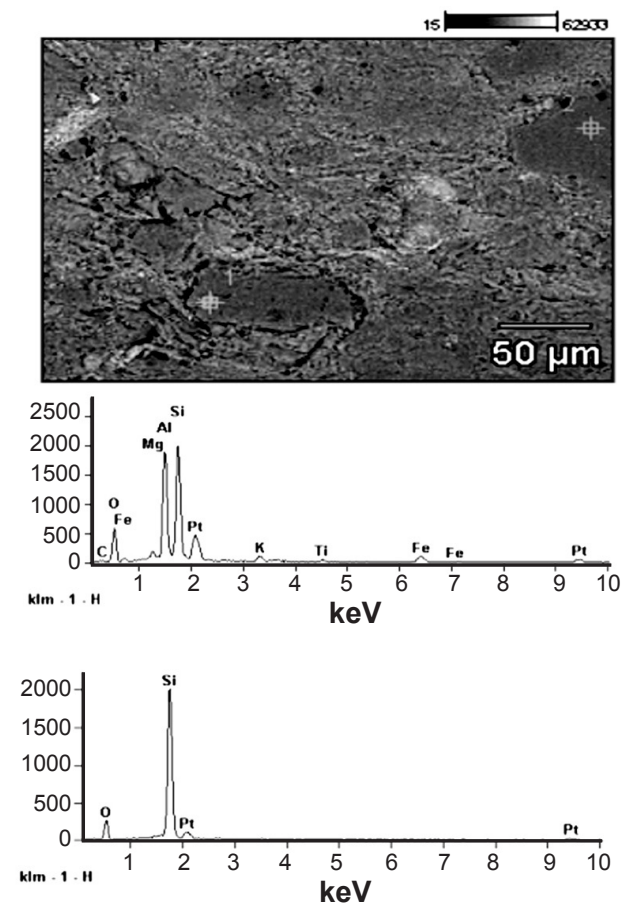
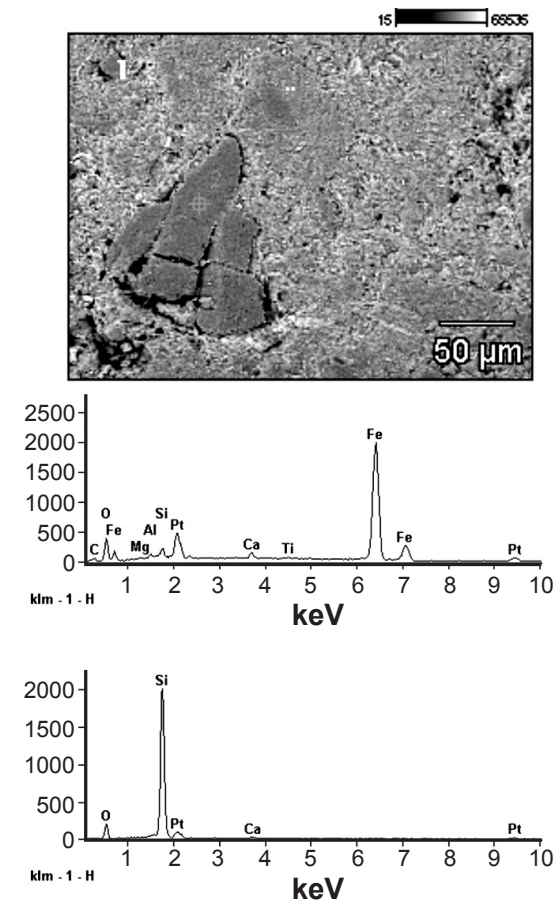
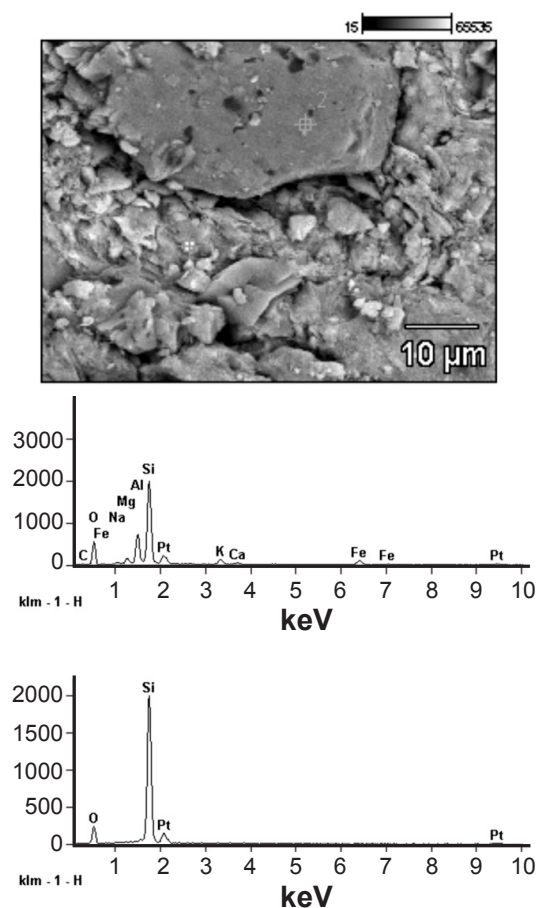

Figura 9: Micrografia obtidas por microscopia eletrônica de varredura com mapeamento por EDS das cerâmicas queimadas a $850{ }^{\circ} \mathrm{C}$. (a) A e (b) B com aumento de 400x, (c) C com aumento de 2000x.

[Figure 9: SEM micrographs with mapping by EDS of the fired ceramics at $850^{\circ} \mathrm{C}$. (a) A and (b) B 400x, (c) C 2000x.] 
A Fig. 8 apresenta micrografias obtidas por microscopia eletrônica de varredura das composições A, B e C. De maneira geral, as três composições apresentam uma microestrutura semelhante com regiões de falhas com uma morfologia grosseira associada a partículas rugosas e poucas áreas lisas. Na Fig. 8 pode-se verificar também que todas as cerâmicas apresentam falhas inerentes à compactação e que ainda estão presentes devido à sinterização ineficiente. De maneira geral, cerâmicas vermelhas queimadas a temperaturas inferiores a $970{ }^{\circ} \mathrm{C}$ não apresentam uma consolidação estrutural eficiente apresentando regiões de porosidade e rugosidade [15]. A porosidade observada nas três composições pode estar associada à eliminação de água e gases durante a queima, vazios oriundos do empacotamento das partículas bem como fissuras entre uma matriz amorfa de alumino-silicato e partículas de quartzo de tamanhos bem variados [4].

A Fig. 9 (a, b e c) apresenta as micrografias das composições A, B e C com mapeamento por EDS. De maneira geral, pode-se observar a presença de $\mathrm{Al}, \mathrm{Si}$ e Fe em todas as composições, ponto 1. Esses elementos normalmente estão associados à matriz amorfa de aluminosilicato. $\mathrm{O} F e$ além de poder estar associado à matriz de aluminosilicato, também pode estar associado às partículas de hematita $\mathrm{Fe}_{2} \mathrm{O}_{3}$ [16]. $\mathrm{O}$ mapeamento em algumas partículas com contornos bem definidos, ponto 2, indicam a existência de quartzo. Esse quartzo pode ser associado à própria mistura argilosa, ao argilito e ao chamote que apresentam em sua composição esse mineral.

\section{CONCLUSÕES}

A caracterização do chamote revelou que esse resíduo é constituído, sobretudo, por quartzo, mica muscovita, hematita e caulinita como fases cristalinas, revelando que os blocos de vedação que o originou não foram queimados a temperaturas superiores a $600{ }^{\circ} \mathrm{C}$. Além disso, apresenta baixos percentuais de óxidos fundentes e granulometria com maior fração "areia", que contribui para ajustar a plasticidade da massa argilosa. A caracterização do argilito mostrou que em relação às argilas utilizadas, ele apresenta um maior teor de óxidos fundentes e menor perda ao fogo. Além disso, assim como o chamote, o argilito atua no ajuste da plasticidade da massa argilosa. De maneira geral, a adição de argilito e chamote contribuiu para o aumento da densidade a seco dos corpos-de-prova. Com relação às propriedades de queima, o argilito contribuiu para reduzir significativamente a retração e a absorção de água da massa argilosa caulinítica queimada a $850{ }^{\circ} \mathrm{C}$. Com relação à resistência mecânica, estatisticamente não ocorreu variação significativa. A adição de argilito à massa argilosa contribuiu para alcançar a especificação para pavimento intertravado para tráfego leve. A adição de $10 \%$ de chamote à composição elaborada com massa argilosa e argilito contribuiu para reduzir ainda mais a retração linear de queima. Entretanto, não ocorreu variação significativa na absorção de água entre as composições B e C. Com relação à composição $\mathrm{A}$, a adição de chamote contribuiu diminuição da absorção. No que se refere à resistência mecânica a adição do resíduo contribuiu para a redução dessa propriedade. As micrografias obtidas por microscopia eletrônica de varredura evidenciaram defeitos inerentes à compactação. As cerâmicas ainda apresentam uma textura rugosa e lamelar indicativa de estágios intermediários de sinterização. Além disso, é notável a presença de $\mathrm{Al}, \mathrm{Fe}$ e $\mathrm{Si}$. São observadas também, em todas as composições, partículas de quartzo evidenciadas pelo mapeamento do Si.

\section{AGRADECIMENTOS}

À FAPERJ (Proc. E-26/103.023/2008) e ao CNPq (Proc. 306027/2008-9).

\section{REFERÊNCIAS}

[1] V. Beltrán, E. Ferrando, J. García y E. Sánchez, Tile \& Brick Int. 11, 3 (1995) 169.

[2] Conorsa, 2010, disponível em < http://www.conorsa.es>, acesso em 10/2010.

[3] E. Sánchez, J. García, V. Sanz, E. Ochandio, Critérios de seleción de matérias primas para la fabricación de pavimentos y revestimientos cerâmicos, Céram. Inf. 157 (1990) 13-21.

[4] C. M. F. Vieira, E. T. A. Souza, S. N. Monteiro, Cerâmica 50 (2004) 254-260.

[5] Manfredini \& Schianchi do Brasil Ltda., Cerâmica Ind. 7, 6 (2002) 34 .

[6] C. M. F. Vieira, S. S. Teixeira, S. N. Monteiro, Cerâmica 55 (2009) 332-336.

[7] S. N. Monteiro, C. M. F. Vieira, Appl. Clay Sci. 27 (2004) 229.

[8] Associação Brasileira de Normas Técnicas - ABNT, NBR 7181: "Determinação da Análise Granulométrica de Solos", Rio de Janeiro, RJ (1984).

[9] C. M. F. Vieira, T. M. Soares, S. N. Monteiro, Cerâmica Ind. 1 (2004) 28.

[10] P. Souza Santos, "Ciência e Tecnologia das Argilas", $3^{\mathrm{a}}$ Ed., Vol. 1 Edgard Blucher, S. Paulo, SP (1992) 397.

[11] W. Acchar, "Materiais Cerâmicos: Caracterização e Aplicações", $1^{\text {a }}$ Ed., Editora da UFRN, Natal, RN (2006).

[12] R. M. Pinheiro, S. N. Monteiro, C. M. F. Vieira, Anais $54^{\circ}$ Cong. Bras. Cerâmica, Foz do Iguaçu, PR (2010).

[13] Associação Brasileira de Normas Técnicas - ABNT, NBR 9781: "Requisitos físicos para a produção de PPC", Rio de Janeiro, RJ (1987).

[14] F. C. Fioriti, A. Ino, J. L. Akasaki, Ambiente Construído 7 (2007) 43-54.

[15] C. M. F. Vieira, S. N. Monteiro, Constr. Build. Mater. 21 (2007) 1754-1759.

[16] C. C. Souza, C. M. F. Vieira, S. N. Monteiro, Revista Matéria 13, 1 (2008) 194-202.

(Rec.04/09/2012, Ac. 10/11/2012) 